\title{
On the State of the Building Industry after the GFC and the Euro Crisis
}

Gerard de Valence and Göran Runeson (University of Technology, Sydney, Australia)

\begin{abstract}
There has been an intense debate in the media and among academics on how the great financial crisis has affected the global economy, and how the effects have differed in different regions of the world. This survey was designed to establish to what extent the building industry has been affected by the GFC and the Euro crisis. Over the last months we have asked senior academics and executives in construction businesses what has happened up to now in their region, what will most likely happen in the near future and in the long term. The answer is that in developed economies the effect has been a substantial downturn as finances have dried up while in developing economies in most regions, demand has been sustained due to population growth with ever increasing needs for residential building and infrastructure. While there is some apprehension about the potential effects of the Euro crisis deepening, no-one seems really worried. In the long term there is an agreement, in developed and developing countries alike, that current business models do not work and that the industry has to reinvent itself to be sustainable.
\end{abstract}

Keywords: GFC, Construction, Construction finance

\section{Introduction}

This year the AJCEB has asked a global sample of senior construction academics and corporate executives for their views on the recent past and near future of the industry in their respective countries. The intent is to get a feeling for the state of the industry around the world during the current financial crisis.

The failure of Lehmann Brothers in September 2007 and the subsequent massive bailouts of banks with toxic asset backed securities and collateralised debt obligations on their balance sheets turned out to be just the first stage in an ongoing financial crisis that in 2011 spread to government debt, particularly in European countries with low growth rates and high debt levels.

Many financial crises in the past have been caused by housing and/or property booms and busts, and the current one is no exception. In America, Spain and Ireland the housing market is in a prolonged slump after heavy price falls, and the Nov. 26 issue of the Economist argued that its house price indicators suggest that the bursting of the global housing bubble is only halfway through. Their concern is countries with high household debt and overvalued house prices, such as Australia, New Zealand, Britain, Canada, Spain, the Netherlands and Sweden.

One of the consequences of the financial crisis has been a withdrawal by banks from lending for building and construction projects in many countries. This is due to three overlapping factors: the requirements for new capital ratios under the Basel III agreement; the safety of government bonds in uncertain times; and weakness on the demand side, partly as a result of tight credit conditions.

To put the AJCEB survey in context the section below is the summary from the McKinsey Global Survey, Economic Conditions Snapshot, Sept. 2011, which covers general economic conditions across all industries: 
As far as executives' expectations are concerned, the Sept. 2011 survey suggests that

only 18 percent of executives in the Eurozone expect near-term improvement in their national economies (compared with 29 percent of all respondents, down from 48 percent in June)

The reason for this, is that they think that:

a double-dip recession will hit advanced economies over the next six months, and nearly three-quarters say there is at least some chance of the Eurozone splintering within the next two years.

On the company level executives' expectations on performance over the next six months:

have fallen, after remaining fairly stable through the spring. The shares of executives who expect customer demand or the size of their companies' workforce to rise have both fallen below a third, and the share expecting an increase in profits in 2011 has fallen to 45 per cent, from 63 per cent in June.

The full McKinsey Global Survey, which provides fascinating reading is available from: https://www.mckinseyquarterly.com/Economic Conditions Snapshot September 2011 Mc Kinsey Global Survey results 2866

In the McKinsey survey the barriers against economic growth in developed countries are seen as low consumer demand followed by economic volatility and lack of credit while in developing countries, inflation is the major concern. This provides the context in which the AJCEB survey should be seen.

Against this background, the AJCEB survey asked three questions from representatives of the major regions in the world:

In your opinion, how has the last few years of economic crisis affected the Building and Construction Industry in your region?

What do you consider likely to happen to the industry, regionally and globally, in the near future?

What about the long term?

In what follows the responses to the questions are given in this order, although all answers to each question are not always included. While the intent is to present the responses in the words and with the focus of the respondents, in some cases the responses have been edited and sometimes rephrased to reduce repetition and make the report more focused.

The replies cover Europe, India, China, Hong Kong, Singapore, Korea, the Middle East, Africa, Australia and South America ${ }^{1}$. We do not claim that this is a representative sample or that this is a statistically valid survey. However, we believe this sort of survey has an important role to fill. One of the respondents wrote in response to the request: "I presume that since you have asked me, you are more interested in opinions than facts . ." This is true, we were and we are. Facts are easy to find but are of little value without the considered interpretation by skilled and experienced experts. That we have got here. We hope you will find, like we did, that these responses are generally thoughtful and in many cases thought provoking, and reflect rather well the intriguingly varied state of the global construction industry. We would like to thank all those who responded to the questions.

\footnotetext{
${ }^{1}$ Unfortunately no-one responded from North America.
} 
Europe covers some of the strongest economies in the world, some that are of real concern to the global economy and a number of countries in between. Given that the focus of the financial markets at the end of 2011 is government debt and growth prospects in Europe this survey will start there. The first response is from Germany, currently one of the saviours of the Eurozone:

For the construction industry, national and regional business cycles are of far greater importance than global interruptions. Only 0.4 per cent of construction investment is carried out by international players.

Germany's construction boom after reunification from 1990-1995 was followed by a deep recession from $1995-2006$, then modest growth till the 2008 crisis. The influence was small, although the financial crisis made it a bit more difficult to get financing. German banks always expected $30 \%$ equity when financing building, and, the value of buildings increased moderately overall.

Germany was destroyed after WWII. Accordingly a big construction boom followed that lasted until 1975 when the country was full of new buildings. Nowadays they are on average maybe 40 years old. Renovation is the future in Germany for many years to come. However, as reconstruction after WWII happened during a short period, there will be another period ahead (maybe in 20 years) when new construction will pick up considerably. Globally there will be few changes for the German construction industry as construction remains largely local.

In the long run l'd stick with conventional wisdom: overall, construction as a proportion of GDP will stay the same. More interesting are local trends and contractors must look out for those.

In northern Europe we had a response from Scandinavia, outside the Eurozone and as far as Norway is concerned, also outside the EU:

The picture is mixed. When Danish property prices began declining a few years ago, construction demand suffered. However, in Sweden a high and stable level of activity due to low rates of interest and the lack of attractive alternative investment opportunities contributed to private sector demand for construction. Sweden has rising levels of household debt and high property prices in the residential sector.

In the short term, there are (in particular in Sweden) rising levels of household debt along with high property prices in the residential sector. This makes construction demand vulnerable to exchange rate turmoil (Sweden and Norway not being part of the Eurozone; the Danish currency is however linked to the euro) in the region. The uncertainties related to the development of major and minor Eurozone economies have obvious global consequences.

In the long term, it is probable that we shall see less concern with price stability, but the effects of higher inflation levels on construction might be ambiguous. If quantitative easing means sacrificing one sacred cow, another cow is the rigorous interpretation of public-private partnerships. Instead, we might see more flexible combinations of public and private investment in major infrastructure projects, with carefully designed schemes for sharing various types of risk.

From the United Kingdom, militantly outside the Eurozone but a sort of member of the EU:

The global financial crisis had a profound effect on UK construction, with a dramatic reduction in workload and forward orders across the industry. Difficulties in financing new projects and dramatic reductions in capital investment in the public sector have led to a very depressed market and to a lack of confidence. Although the worst may be over, continuing instability in the EU has maintained low confidence, and the very real prospect of stagflation suggests that things are unlikely to improve in the short term. 
Perhaps the only positive relates to skills availability; skills shortages have all but disappeared, particularly given the abundance of labour from Eastern Europe and Ireland following their economic downturn. Will this have a detrimental effect on the industry's ability to reproduce skills?

The UK industry remains in a very difficult situation, with forecasts suggesting that only private sector housing and infrastructure will see any growth over the next few years. Even if there were a marked increase in output, this is unlikely to translate into a major increase in employment in the short term. Government initiatives may stimulate growth in the near future, particularly in terms of the Green Deal, a scheme to retrofit existing housing stock which would be paid for through increases in utility bills. It remains to be seen whether such schemes will be embraced by home owners and they will do little for the commercial building sector in any case. It is likely that the next few years will be very difficult for the industry in the UK.

Further out, the outlook for infrastructure is particularly strong sand the nuclear programme will sustain growth. The acute housing shortage in the UK is also likely to stimulate growth. It remains to be seen, however, whether we will see pre-2007 levels of activity again.

\section{Also from the UK with a stiff upper lip in the face of adversity:}

Since the beginning of the financial crisis, things have panned out in a somewhat strange way. First, the impact on the construction sector was a long time coming. There were many public sector projects already in progress, which was part of the government's problem at the time. They had continued to spend on major public sector projects at considerable rate, and all those major projects in the pipeline kept construction companies in work, though at a more relaxed rate until well after 2010 general election. The new government soon discovered that the adventurous public spending by the previous administration had all but exhausted the countries reserves, so a comprehensive public spending review soon put paid to many planned construction projects.

As work for the construction sector finally dried up, new major projects were announced, and the tap of public sector investment was quickly turned on again, to try to avoid too many insolvencies and consequent redundancies. Thus, while there is not a lot of work about, the public sector investment programme has maintained a low level of work that seems to have provided a buffer. But the private sector has slowed significantly, largely through the disappearance of capital markets. Once the full impact started to hit the construction sector, insolvencies were seen to rise much higher in the construction sector than in others, with a $20 \%$ increase in some quarters, compared with the previous year. But most of the time we seem to be seeing insolvencies running at about $10-15 \%$ higher than the previous year. Of course, these headline figures are increases, not the proportion of companies disappearing. Headline grabbers are great for creating disquiet.

In the near future, few developers will be able to raise capital from banks, because the banks do not have any. Clearly, this is a very lean period for the construction sector. Construction workers are being laid off and a proportion of business are disappearing. Since most work is sub-contracted, the sector is very resilient. Those contractors and suppliers with workflow are now in an odd situation, because if they are making profits, there is a real problem in terms of what to do with their reserves. Contractors typically manage their projects so that there is a positive cash flow, ensuring that payments out are always some weeks behind payments received. Few people seem to notice that this means contractors do not need to invest in projects; their clients do. This positive cash flow means that contractors with projects have surplus cash to invest, typically in developments of their own. But in such an austere period, the markets into which they sell their own developments are somewhat moribund. Since this is often quite lucrative, times are hard. 
In the longer term, locally and globally, I feel that there is chance the construction sector might be able to finally move away from being a cash cow. If we are to make this into a 21st century business sector, it is essential that we abandon the Victorian business models and ideals that have served us so well throughout the 20th century. I sense that there is an opportunity for businesses to take more of a stake in the things that they are producing. If we can get contractors and trade contractors to invest in the things that they make, and take a greater proportion of their payment after completion, then we shall see greater incentives and rewards for innovative products and practices. And what better time than now to enable large, successful companies to pump-prime their clients' developments with cash? Many more contractors are establishing capital arms to invest in their own and their clients' projects. This is interesting. If it continues, we could see the end of a business sector based on large volumes of cash being pumped around construction sites, and the emergence of significant investment-driven construction companies which will be able to weather financial storms as successfully as any other business sector.

The developing world is quite different to Europe. Most countries present an optimistic picture, e.g. China, India South America and Africa although there are dissenting voices form the Middle East and Korea which both have been very badly affected by the economic crisis. From the rest it is: "What crisis?". The construction industry is alive and mostly booming.

Starting in India the current situation and the future is bright with the industry driving the economy at high speed:

India and more particularly the NCR (National Capital region) and Mumbai have witnessed very hectic building and construction activity on account of few factors. Firstly, in NCR leading up to the CWG (Commonwealth Games) infrastructure - roads, flyovers, metro, stadiums and buildings were under construction with a timeline. In Mumbai, due to booming real estate industry the building and construction activity was high.

Secondly, the real estate boom due to genuine demand for housing and commercial buildings has led to private developers having sold off the plan projects. The construction for those sold projects has been happening. Projects in this part of India continue to be launched, sold and constructed at a steady pace on account of jobs being created in this part of the country faster than other parts.

Labour for building and construction industry is in short supply and securing a trained workforce is always a challenge for all contractors, especially because construction industry in India is labour intensive as compared to other economies. Due to the National Rural Employment Guarantee scheme, fewer workers are choosing to come to cities from rural settings, which may lead to more mechanization and construction processes suited to the new market conditions.

In the near future, the building and construction industry is expanding across the country, creating inflationary pressure with raw material prices increasing especially for steel and cement. This is causing an increase in construction costs, testing the commitments of developers. Infrastructure projects are also hit with the inflation with budget constraints leading to delays in delivery.

In the long terms the above shortage of labour would lead to more mechanization on site. Vocational training for trades in the building and construction industry in India would get a push. All this would lead to better quality delivery of end product.

This leads us to China where all is well, but where there may be some dark clouds on the horizon:

China's construction market has been booming over the last three years, although for some time now, everyone has predicted that the global economy will cause a 
significant down-turn. After the 2008 Beijing Olympics, infrastructure works started to slow down with the major projects completed well before the Games, however the property market fueled by internal demanding, rocketed for another two years and property prices doubled or even tripled in that time. The government responded by keeping a very tight control on the acquisition of land and used fiscal tools to cool down the market, and were successful as now, there are fewer and fewer new projects being undertaken. The same happened in Shanghai after the World Expo in 2010, and may happen again in Shenzhen after the International University Students Athletics Event.

Different segments of the construction market react differently. In Beijing, while the residential market boomed for two years before grinding to a halt some months ago, the construction of hotel projects slowed down significantly after the 2008 Games. Office buildings have been in oversupply for some years and not many new projects are currently under construction. Retails projects, on the other hand, have been bright spots since the domestic demand is still growing drastically with the government encouraging domestic consumption. Industrial construction is never an important sector. Perhaps due to concerns about an aging population, demand for health and age care facilities is likely to grow significantly in the coming few years.

In conclusion, the global influence on the Beijing market has not been strong in the past few years; sometimes it even seems like when the rest of the world is failing investors re-direct their investment to China and its big cities like Beijing and Shanghai. However, in summary, the construction market is a bit below the 'normal' level of activities at the moment.

Even within China, not all big cities behave the same. In the second tier or smaller cities the construction market has been booming for the past three years because of the great residential needs of the giant population in China. If we see China as a region, then due to such demand for better housing, it is likely that the residential market is still dominating the construction around China. Great infrastructural needs within the developing cities as well as inter-city transport and communications will ensure that the construction market in China is ever developing and booming. As long as the basic/traditional concept of buying and owning home remains central to the Chinese population, this will persist until very last day of the world, I believe.

As far as the global construction market is concerned, in developed economies with static populations like Europe and North America, the influences will be economic and political and I can see no change in the next few years. If Australia can attract more migrants, then the construction in all sectors will grow as well. I believe that the growth of population will determine the demand for construction although commercial buildings will continue to be subject to global economic factors. China is an exception at the moment because of low levels of construction for the last 100 years.

\section{From Hong Kong, very dependent on events in China:}

There is no significant effect from the economic crisis over previous years on the building and construction industry in China Mainland, nor in Hong Kong. This is largely because the construction sector is a major driving force for the national economy and the government has ensured that the sector continues to lead the economic development

The industry will continue to grow particularly in those developing countries such as China where huge plans for urbanization are under implementation. China has set an example to other developing countries that the construction for urbanization can contribute to the development of national economy, thus other developing countries particularly in Asia will position the construction sector as a priority in their policy making. Globally, the construction sector in developed countries and regions will have to make major reforms to the way the production process engages with sustainable development principles. 
Building and construction will play an important role in promoting sustainable development. The traditional practice both for construction production and management has to be changed. A kind of new culture in the industry will emerge.

From Singapore, in South-East Asia but also influenced by events in China, the respondent explains how short term financial problems have been avoided in the region but looks at the long term problems not only in financial terms but also in terms of technology to deal with the two major issues of the environment and terrorism:

The economic crisis has certainly rattled the confidence of many countries in Asia. However, interestingly enough, it appears that the building and construction industry in the region has not been affected as badly as what some doomsayers might have ventured to predict. On the contrary, the building and construction industry in China, the powerhouse of Asia, has grown from strength to strength, with the Chinese government pouring in huge investments in upgrading existing and creating new infrastructures with a view to stalling the onset of a flagging economy that might result from the lacklustre economic performance of Western countries, particularly the US. Funds fleeing from the West, and pouring into Asian countries, further stimulate growth in the building and construction industry, with ample liquidity fuelling insatiable demand for investment properties.

Coupled with the speculative element, property prices went through the roof in some countries (for example, in Hong Kong and Singapore). While many properties in the US went into foreclosure, the Asian property market seemed to remain unperturbed. From the public sector point of view, the economic crisis appeared to be an opportune window for many Asian governments (for example, China, Vietnam, Indonesia, Malaysia and Singapore) to bring forward their infrastructure work-plans, capitalizing on the pump-priming effects of such built investments to stimulate backward-andforward growth linkages in other lagging economic sectors, and reaping the benefits of lower tender prices with hungry construction firms competing more aggressively for jobs.

As for the near future, the economic crisis has also surfaced the need for financial prudence in the building and construction industry, which run parallel to increasing evidence of the adverse effects of global climate change. The sustainable agenda is likely to feature more strongly and prominently in the industry, both regionally and globally. While funds continue to pour into the industry, investors are increasingly looking towards buildings that are sustainable in terms of energy use and recyclability. Carbon neutral buildings will increasingly be brought to the drawing board as running costs of buildings can be an undue burden for owners in the life-cycle of the built assets. The growth of eco-cities is likely to perpetuate both regionally and globally. In tandem with this trend, it is expected that the education and training needs of building professionals have to be reviewed and/or revamped to meet these challenges, balancing financial prudence with sustainability goals in the built environment.

In the long term, the global Financial Market, the Natural Habitat and Terrorism are three areas worth watching with respect to developments in the industry

The world will continue to watch developments in the Financial Markets in the US and the European Community, for signs that may possibly lead to a financial meltdown that was narrowly averted in 2008 only through quantitative easing (QE) measures implemented by the Obama administration. The world will continue to watch to see if the QE is only a temporary stop-gap measure, and that a global depression cannot be averted. This coupled with the financial problems in the Euro-zone (particularly in Portugal, Ireland, Greece and Spain or PIGS as well as Italy) are cause for concerns. The health of the global financial markets certainly has vast implications for the wellbeing of the building and construction industry.

The Natural Habitat is another area worth watching in the long term. Increasingly, the world is witnessing more natural disasters and calamities, from flooding, hurricane, 
earthquake, tsunami and raising sea levels. The building and construction industry must rethink how technologies can relate to and pro-actively account for such events to safeguard lives and properties. This is particularly important in small nation states (such as the Maldives, Tonga, Vanuatu and so on) whose very existence is being threatened with each passing day. Sea defence systems, floating cities, etc. are some of the issues that have not been brought to the forefront for active engagement globally.

Terrorism has taken on a more global dimension in recent decades, the most devastating visuals being the 911 attacks on the World Trade Centre in New York, US, the Mumbai attacks, among others. Terrorism has immense implications for the building and construction industry, both for new and existing buildings, and in all parts of the world.

From Africa there were two responses. The first, from South Africa, paints an optimistic picture of the long term future after some consolidation in the short term:

The 2010 World Cup, together with stringent foreign exchange controls, played an important role in protecting the South African construction sector from the global financial crisis. The development of numerous sports facilities and airports across the country underpinned the performance of the sector between 2008 and 2010. Yet the South African economy has slowed significantly in recent months, and this is having a negative impact on the sector. Recently published figures by the Bureau for Economic Research (BER) suggest that the building sector is rapidly contracting. This is true for the residential, commercial and civil sub-sectors. The public sector has stalled numerous projects and the private sector is largely experiencing an excess of retail and office space. It has been estimated that the sector is operating at a level some $10 \%$ lower than two years ago. Forecasts for the next two years suggest that the sector will see growth below $10 \%$ per annum.

In Africa, the building sector is being stimulated by relatively high levels of economic growth. Forecasts suggest that economies such as Nigeria, Ghana and Angola , will, on average, be recording economic growth rates in excess of $8 \%$ per annum in the next few years. This will largely be driven by the mining and petroleum sectors. These countries also need to improve their infrastructure in order to facilitate further economic growth and development.

It should be underlined that the economies of Africa have, to a significant degree, been decoupled from the financial crisis that raged through North America and Europe. This has protected the construction sector across the continent.

In the short term the sector will likely continue to consolidate and shed employment opportunities. This will largely be caused by a decline in public sector infrastructural expenditure. The private sector will also continue to find it difficult to raise the finance in order to undertake commercial and residential developments and this will have a negative effect on the construction sector. Added to that, the commercial and residential sectors need to mop-up excess retail space before commencing new developments.

The poor performance and uncertainties related to the European economies will, in the short term, continue to have a negative impact on investor perceptions and their willingness to undertake new developments. The continuing Greek debt crisis, and its potential impact on the Eurozone, is worrying in this regard.

In the longer term, the African continent will offer exciting opportunities, driven by relatively high levels of economic growth and improved investor perceptions. The shortage of housing across the continent will also remain an important driver for the sector. 
The urbanization of African cities will in the longer term place significant pressure on the existing infrastructure and this will invariably offer opportunities for the construction sector. Investors will also continue to focus on the telecom, mining and energy sectors.

In South Africa, significant attention is being given to the development of rapid transportation systems. It is likely that this infrastructure will offer construction opportunities in the public as well as private sectors. The demand for low income housing in South Africa will also drive the sector.

The second is from Nigeria where the financial situation has made more of an impact and changed the balance between local and expatriate companies to the detriment of the former due to an increasing reliance on PPPs:

The construction industry has remained one of the most vibrant and active sectors of the Nigerian economy in recent years. The increased funding of the housing sector by the private sector, several integrated power plants, development of rail transportation, establishment of free trade zones and industrial zones and several road projects going on in the Federal Capital Territory (FCT) and all the states in Nigeria have increased the tempo of construction in recent years. The situation which has created huge investment opportunities and markets for both local and foreign investors brought about several issues of major concern to stakeholders and non-stakeholders alike. Among these issues are local and foreign participation, duties of construction professionals, collapse or failure of structures, high cost of construction inclusive of construction materials and the issue of fake or inferior construction materials.

The construction industry in Nigeria has in the last few years been dominated by expatriate (foreign) contractors. The economic crises of the last few years coupled with the inability of governments (Federal, State and Local) to get the funds to finance required infrastructural projects has brought about a shift from traditional procurement approaches to the modern partnership approaches of Public-Private-Partnership (PPP) specifically in infrastructures.

With the current economic crisis, local (indigenous) contractors do not have the financial capacity for such partnership therefore; expatriate contractors remain the sole beneficiary of the partnership. The effect of foreign domination of construction contracts in Nigeria is noticeable in the construction cost index. Despite the economic crisis, construction costs remain on the increase such that the costs of construction in Nigeria are considered as the highest globally. The situation has brought about the need for standards in construction costs and increased local content in construction. The Nigerian Oil and Gas Industry Development Content Act of 2010 has set the pace for local content in Nigerian economy, therefore a similar Act for the construction industry is expected in the nearest future.

From South America there were two responses. The first is from Brazil where things are going splendidly:

Due to a combination of factors the Brazilian construction industry was not affected by the world economic crisis, going through the best period of growth since the mid seventies, partly because the Brazilian economy was not strongly affected by the economic crisis. Moreover, the government decided to invest strongly in the construction sector, especially in the social housing market. There is also much investment in infrastructure projects. Some residential building companies have increased their turnover fivefold. Prices of dwellings have also increased considerably. As a consequence there is a shortage of materials and labour. Some companies are also facing problems in the quality of management for a much larger number of projects (and for bigger projects). 
I do not think the country will slow down much until 2014, at least. One of the immediate consequences is the use of prefabricated components. Many companies have also decided to hire their own labour, rather than using subcontracted labour only. By doing that, they can have more control over their crews and provide incentives to reduce labour turnover. If the boom continues for a while, it is a unique opportunity for developing the construction sector, especially in terms of moving towards industrialized construction. There may also be a positive impact in terms of industrial relations.

Our second respondent from South America (Chile) also sees the current situation as very good but can see warning signs in the future if the Euro crisis is not resolved:

South America and Latin America have not been strongly affected by the economic crisis. After 2009 things started moving again. This year is going to be very good here in Chile and in general around the region. The growth of the construction sector has been strong (6-8\%) pushed by favorable economic conditions of most of the countries until now. Particularly Peru, Ecuador, Brazil, Argentina, Colombia, Chile have been doing quite well during the last two years.

If there is a European recession as it is feared, it is expected that economic growth will go down and so, the construction industry growth. However, if the crisis is solved, then the growth will recover and construction will do okay. In any way, economic expectations are already affecting the market to some degree and some projects are being delayed for a while.

If the economic crisis is solved and the world start growing again at good/normal rates, I believe that countries of the regions will perform well and so will do the Building and Construction Industry. This region is in need of many infrastructure, building and industrial projects and development and those needs will push the industry for many years. But it depends on the stability of the world's economy, particularly China, USA and Europe.

While so far developing countries have been doing well, this is not uniform as the reports from Korea and the Middle East show. First the response from Korea:

In Korea, the global economic crisis in 2008 deeply influenced the construction market. The decrease between 2007 and 2011 was around $20 \%$, and very serious in private housing. The effect has caused bankruptcy of many local construction companies, sacking of employees, unemployment crisis to university students, and so on.

The financial problems cannot be solved easily and may continue for some years, so the downturn of Korean construction may be prolonged and many companies which have been just surviving will be collapse.

The financial crisis in many advanced countries cannot be easily resolved due to domestic politics, increased social security, average life extension, and so on. Also in Korea populist trends in politics is gaining ground, causing increases in welfare and decreases in SOC. These trends and decreases in the birthrate means reductions in the construction budget. If there is no drastic change in Korea such as for example the unification of South and North Korea, about 5 years of a weak construction market is expected.

There are also problems in the Middle East:

The economic crisis has deeply affected the construction industry in the Gulf Cooperation Council (GCC) region, especially the private real estate development sector, where many projects have stopped, real estate developers' stocks have sharply dropped, and land prices have taken a nose dive. Consequently, many investors have suspended most, if not all, of planned future projects. However, the rise 
in oil prices has encouraged the government to pump more liquidity in the market and accelerate the developments already in the pipeline, a measure that, to a certain degree, has lessened the effect of the financial crisis.

The impact of the crisis, however, is expected to last for many years to come, and it is anticipated that the construction market will witness a "reshuffle" among the various industry players, where only the strongest, both financially and technically, shall survive. As the case with most developing countries, the civil engineering and building construction cycle is expected to rise again within the coming few years, nevertheless, more towards the public rather than the private sector, with more emphasis on PPP and PFI procurement methods.

Finally, there were two responses from "the lucky country", Australia which show that maybe, we are not quite either as lucky or as unlucky as our politicians try to tell us. The first one looks at the changes in the industry that are taking place:

The industry has changed considerably. The bread and butter commercial building work has dried up and firms have had to be innovative and adapt to new micro markets such as university buildings or be opportunistic in responding to one-off iconic projects. Business strategy has therefore become much more short term and dynamic. This has meant that construction firms have had to learn new business models and sectors that perhaps they would not have in ideal core business conditions.

One area where the larger firms have sought to diversify into is the resources sector. These incredibly large projects pose many new human resource and logistical risks which are not well understood by those who have traditionally not operated in this sector. The many years of fragmentation of the industry have also now come home to roost in the skills shortage which we see in the resource sector. Companies are having to recruit heavily from overseas to resource these projects so there will be a large influx of foreign workers into Australia at an operational and managerial level. The credit crisis has also affected the PPP market adversely although this is expected to pick up again in the future as credit becomes more available - particularly in the roads and infrastructure sector - which is likely to be a source of future work.

In the near future, there will inevitably be an increase in foreign competition locally and regionally. What was a domestic industry will become more internationalized as foreign firms immersed in depressed overseas markets look to distant shores for work opportunities. Chinese, Japanese and EU firms are seeking to buy up companies as a road into the Australian construction sector and are starting to take work off local contractors. Many foreign firms have been burnt in the past but will be a lot smarter this time around.

The long term outlook surely can't be anything other than better than the current outlook. The economy will also recover as confidence recovers. But this will be a slow process as EU seeks to restructure its debt over the next 5 years. I think that BIM will have an enormous impact on the industry, changing traditional relationships and I believe that the so called green revolution will gather pace and fundamentally change the industry - at least on the outside.

\section{The second Australian response:}

For PPP/PFI deals the GFC certainly made financing projects difficult, but did not stop activity in Australia with several significant infrastructure projects being financed. Many other major infrastructure projects were already under construction. The Australian construction market has been overheated for the last five years with supply constraints pushing up prices, exacerbated by the resources boom in recent years. Softness in the residential and commercial sectors has helped by taking some of the demand pressure of construction resources. 
In the near future, continuing growth in demand for engineering resources is likely to continue driven by growth in the resources sector with significant shortfalls of skilled labour. There is also a strong pipeline of work in infrastructure including road, rail, ports, airports, hospitals, schools and defence facilities. The European sovereign debt crisis is having a positive impact on financing for Australian PPP/PFI projects with flight to quality in evidence. Many foreign equity houses are investing in Australian infrastructure projects with triple A rated state or federal government cash flows. Foreign banks are actively competing with the locals for a piece of the debt finance action with reductions in margin spread and increases in tenor.

Longer term there will inevitably be a turnaround in the resources sector but China is unlikely to stop growing for the foreseeable future. India is also becoming a significant economic powerhouse. Unfortunately all this resources growth has led to appreciation of the AUD with negative impacts on both the industrial and services sectors. This has greatly narrowed the base of Australia's economic diversity and we are becoming very vulnerable to any collapse in the resources sector.

There is a significant backlog in transport infrastructure in Australia that could feed the Construction industry for decade so long as there is enough wealth to pay for it all. While the resources boom continues the growth in wealth continues and this is unlikely to change dramatically for the next 3 to 5 years.

\section{Concluding Comments}

The pattern that is developing to some extent follows the McKinsey survey findings in finding a significant difference between developed and developing countries. The financial crisis has had a major impact in Europe and is expected to continue to affect the industry in the near future.

In contrast, in developing countries, it is the population growth, urbanisation and infrastructure development that are now and will, over the foreseeable future, be the driving forces behind the demand for building and construction. McKinsey has a map of global cities that captures the scale of this trend, (http://www.mckinsey.com/lnsights/MGl/ Research/Urbanization and go to the interactive map of global cities). The map shows 600 cities with their population, GDP and GDP per capita growth between 2007 and 2025 and underscores the importance of these developments for the future of the construction industry.

Another thing to come out of the survey is the conviction that the nature of construction will (have to) change. Whether it is the approach to technology, to new business models, to sustainability or investment, there is a near unanimous assumption that we need to do things differently if we are to adapt to trends in the long term.

Maybe the final word should go to the respondent from Singapore, who has given us our long wished for first opportunity to publish something in Chinese - although very short - by pointing out that the Chinese word for "crisis" is written as:

\section{危机}

This is pronounced as "wei qi"; "wei" being danger and "qi" being opportunity. This should remind us that even in the midst of a crisis, opportunities will still abound if one is well prepared. As evidenced by this survey, we have at least given it a lot of thought. 